\title{
A Note on the Activities of a Solitary Male Baboon
}

\author{
MONTGOMERY SLATKIN \\ University of Chicago \\ and Glenn Hausfater \\ University of Virginia
}

\begin{abstract}
This paper describes the behavior and activity patterns of a solitary adult male yellow baboon (Papio cynocephalus) living in the Amboseli National Park, Kenya. Social events surrounding the male's departure from his group, his contacts with other baboons while solitary, and events surrounding his return to the group are described in detail. The distribution of the male's time among several activity states, called his time budget, the average duration of these activities and the autocorrelation of activity states are analyzed and compared to the same measures of activity taken on group living males. The information presented indicates that a solitary male, even when injured, is not necessarily destined to die or to have a low reproductive potential.
\end{abstract}

\section{INTRODUCTION}

This paper describes the behavior and activity patterns of a solitary adult male yellow baboon (Papio cynocephalus), adult male BJ, living in the Amboseli National Park, Kenya. Observation and sampling of this male's behavior commenced in June, 1971, and continued through September, 1972. Subsequently, the male was under observation in June through September, 1973, and in May through August, 1974. During most of August through October, 1971, adult male BJ lived a solitary existence. Thus we have extensive information on the behavior and activities of this one individual before, during, and after his period of solitary life. Although the behavior and activity patterns of a single male is clearly a small sample on which to base any generalizations, we believe these observations to be of sufficient theoretical and methodological importance (as discussed below) to warrant a separate communication.

The existence of solitary adult males has been reported in almost every Old World monkey species, yet in spite of their widespread occurrence, very little is known about the origin, behavior, or activity patterns of these individuals. These solitary males are probably of great significance with respect to primate population dynamics (CoHEN, 1969), population genetics (NozAWA, 1972), and reproductive strategies (HAUSFATER, 1975; SADE, 1968). Thus, the circumstances under which an adult male primate entered and left a solitary mode of life, the duration of solitary living, and his activities while solitary are important information for primate biologists. Studies of solitary males have been carried out previously on several macaque species, but with few exceptions the data are largely anecdotal and have been collected largely in provisioned populations: NisHIDA (1966) and KAWAI et al. (1968) reported on the behavior of solitary adult males among Japanese monkeys (Macaca fuscata), both 
through direct observation and by means of radio-telemetry. Simonds (1973) discussed the relationship between solitary males and group structure in bonnet macaques (M. radiata); Koford (1966), KAUfMAN (1967), SAdE (1968), and LindburG (1969) provided notes on solitary males among rhesus monkeys ( $M$. mulatta) and BURTON (1972) briefly discussed solitary male barbary apes (M. sylvana).

Furthermore, solitary males provide an important research opportunity in the study of primate ecology. In the same habitat, solitary males and group living males can be assumed to share the same nutritional and ecological requirements. However, solitary males lack the regular and sustained social encounters and social stimulation experienced by group living males. Hence, the activities of solitary males should primarily reflect ecological factors, e.g., food plant distribution and abundance, while the activities of a group living male would be influenced both by ecological factors and by social factors, e.g., behavioral synchrony, social facilitation, etc. Thus differences in the activity patterns of group living males as compared to solitary males must be a consequence of group life or sociality rather than a consequence of different ecological constraints on the behavior of these two classes of adult males.

\section{STUDY SITE AND METHODS}

In June through September, 1971, the authors were carrying out separate, but related studies of individuals in one group, "Alto's group", of yellow baboons (Papio cynocephalus), in the Amboseli National Park, Kenya. The ecology of the Amboseli study population has been described in detail by Altmann and Altmann (1970) and our studies were conducted as part of their ongoing long term study of Amboseli baboons. The social organization and mating system of Alto's group has been described by Hausfater (1975); SLATKIN (in prep.) gives a detailed analysis of activity patterns and time budgets of adult males in the group. As part of the study of activity patterns and time-budgets, the first author carried out detailed sampling of the feeding behavior of four adult males, while as part of the social behavior study, the second author sampled adult males, adult females. However, in early August, 1971 , when $B J$, one of the adult males under study by both authors, departed from Alto's group, observation of him outside the group was continued to document changes in his activity patterns and behavior resulting from his changed social condition.

Adult male $B J$ was followed continuously from 0800 to 1800 hours for seven days after his departure from the group; all observations were made from a field vehicle while following several hundred feet behind the male. During observation periods, $B J$ 's activity state was recorded each minute, on the minute, and his encounters with other baboons were described in detail. Data were either entered directly onto prepared data sheets or were dictated into a portable tape recorder and later transcribed verbatim. In addition, $B J$ 's location and day ranges were mapped at half-hour intervals throughout the day on a standard base map of the study area (ALTMANN \& AltmanN, 1970). After 11 August 1971, $B J$ was observed intermittently until late October, 1971, when he rejoined Alto's group and was again under daily systematic 
observation by the second author. Further details of behavior sampling methods for pheca art of this study will be given below.

\section{SOCIAL BEHAVIOR \& MOVEMENTS}

\section{4-5 August 1971: Departure from the Group}

When this study began in July, 1971, $B J$ was the third ranking of eight adult males in Alto's group. On 2-4 August 1971, BJ was in consort with an estrous female, Lulu, though the consortship was terminated abruptly in the afternoon of 4 August, 1971, when $B J$ received a long $(5-6 \mathrm{~cm})$ deep slash wound on his left hindleg and several small puncture wounds on the left knee. Neither the actual fight nor the individual responsible for the wounds were observed, but second ranking male Ivan received a small wound at about the same time and was subsequently in consort with Lulu. On the morning of 5 August 1971, adult male $B J$ limped away from the main portion of Alto's group and lay on the ground in the shade of a shrub; his leg wound dripped fluid, his locomotion was greatly impaired and his breathing seemed labored. During most of that morning, $B J$ trailed along about one half kilometer behind the group and spent much of his time lying in the shade, though by midafternoon he had gradually become more active and resumed feeding at a normal rate.

During the morning of 5 August, $B J$ followed almost exactly the same course as the group, but remained at least 200 meters from the group at all times. He was not observed to interact with any other group member. At approximately 1500 hours, the other members of Alto's group drank at a permanent waterhole (KH5, AltmanN \& ALTMANN, 1970) and then shifted from a northward course to a generally southward direction, eventually returning to the same sleeping grove from which they had departed that morning. In contrast, $B J$ did not drink with the group or shift course, but continued northward and drank by himself at another waterhole ( $\mathrm{KH} 4 \mathrm{a}$, Altmann \& Altmann, 1970). That night $B J$ slept in a grove that had not been occupied by the study group in the previous two months of observation (though it was used by the group later); he had traveled a total of $4.3 \mathrm{~km}$ by nightfall.

\section{6-11 August 1974}

For the next six days $B J$ 's day ranges showed no correlation with the day ranges of Alto's group and on only one occasion did $B J$ actually come into social contact with Alto's group. In fact, on most days several kilometers separated $B J$ from Alto's group. On 6 August 1974, $B J$ traveled a total of $6.7 \mathrm{~km}$, though most of the midday hours were spent resting or casually feeding. $B J$ spent that night in a grove only rarely used by other baboons. On 7 August 1971, BJ was under observation only until 1011 hours at which time he disappeared into thick bush.

On 8 August 1971, $B J$ was relocated at 0929 hours and was followed until his ascent into sleeping trees at 1830 hours that night. When $B J$ was initially located on this morning, there was another solitary adult male baboon nearby. This second male chased and fought $B J$ from approximately 0930 to 1200 hours; during this two-anda-half hour period $B J$ continually gave submissive behaviors-m grimace, cackle vocali- 
zation, tail-up (see HAUSFATER, 1975, for complete descriptions)-toward the other male. In this extended agonistic bout, $B J$ received two new wounds, each about $2-3 \mathrm{~cm}$ in length, one on each side of his muzzle. In addition, his leg wound was reopened and was bleeding freely at the end of the chase.

The contact between the two males ended abruptly. At approximately 1100 hours, the other male chased $B J$ into the terminal branches of a fever tree (Acacia xanthophloea); $B J$ hung precariously in the tree for over 45 minutes. The second male then suddenly descended the tree and walked away, disappearing from view into a patch of tall grass; he was not seen again that day. During the rest of the day, $B J$ gradually recovered from the chase, but was limping badly. He spent the afternoon foraging on a wide expanse of open savannah north of a major waterhole and did not interact with any other individuals or groups during the remainder of the day. His total day range was $7.2 \mathrm{~km}$ and he spent the night in a single isolated moribund acacia tree. On this and all other nights during his isolation, $B J$ slept in a tree that had a fallen limb forming a ramp from the ground into the canopy.

Throughout the next two days ( 9 and 10 August), male $B J$ did not contact other individuals or groups. He traveled a total of 5.6 and $2.7 \mathrm{~km}$ respectively on these two days. Both observers were impressed with the casualness of $B J$ 's behavior, particularly that he showed no hesitation either of entering thickets and tall grass that easily could have concealed predators, or of feeding on, or crossing, large expanses of treeless savannah.

On 11 August, $B J$ foraged by himself during the entire day. At 1740 hours, $B J$ moved east from the open plains toward sleeping trees around a small waterhole (KH1, Altmann \& Altmann, 1970). This was the same waterhole where $B J$ had encountered the other adult male on 8 August. When about two kilometers from the grove, but in view of it, $B J$ turned and began running in the opposite direction. From the grove, the same male with whom he had fought on 8 August came charging at $B J$ and another protracted agonistic bout followed. For the next one and one-half hours, the other adult male chased and fought with $B J$, who again responded with intense submissive behaviors. As before, $B J$ eventually ended up hanging from the terminal branches of an acacia tree and the entire agonistic bout was terminated when the other male descended the tree and walked back toward the groves from which he had come. $B J$ did not again attempt to approach these groves, but spent the night in the same tree into which he had been chased, a tree in which baboons were never again observed to sleep. $B J$ had traveled $8.0 \mathrm{~km}$ this day.

Only casual and intermittent observations were made on $B J$ from 11 August 1971, until late October, 1971; these observations will be summarized below. However, the following features of $B J$ 's behavior during the above seven continuous days of observation were noteworthy: (1) $B J$ 's departure from the group occurred in just a few hours' time; male $B J$ was not peripheral to the group for any extensive period. (2) $B J$ 's departure from the group was coincident with a violent fight, with his severe wounding, and with the presence in the group of an estrous female with whom he had consorted. (3) Once solitary, $B J$ utilized all of the same habitat types-tall grass, treeless savannah, shrub thicket, etc.- -as did group living baboons. $B J$ drank at the 
same waterholes used by group living baboons, and his drinking bouts were unusual in that he often drank continuously for longer than a minute.

\section{ACTIVITY PATTERNS AND TIME-BUDGETS}

The temporal pattern of $B J$ 's activities during the period of detailed observations will now be considered. For the purpose of the time budget analysis, each individual's activities were divided into four nonoverlapping categories: feeding, moving, resting, and social behavior (SLATKIN, in prep.). These categories were so defined as to be exclusive and exhaustive, and thus at any time, a focal individual was in one and only one activity state.

Briefly, the activity states were defined as follows:

Feeding: All activities associated with obtaining and eating food-digging, pulling, cleaning of food-are included in this category. Short locomotor movements while feeding, such as sliding or scooting, were scored as feeding so long as the distance transversed was less than one full stride. Chewing of food items seemed to be independent of other activities, including feeding, and thus an individual who was chewing while walking was scored as moving. With the feeding category defined in this way, the amount of time an individual spent feeding should be directly related to the amount of food he gathered.

Moving: Individuals walking or running on the ground or climbing in, sliding on; and (on occasion) falling from trees were recorded as moving.

Resting: All sedentary and solitary activities not associated with feeding were lumped in this category. This included sitting alone, sleeping, and such solitary behaviors as autogrooming.

Social Behavior: Only those social activities that actually prevented an animal from feeding at the same time were included in this category. By far the most common activity in this category was social grooming, but some time also was spent fighting, chasing, presenting and mounting. There were many other activities that clearly had some social significance but that did not prevent an individual from feeding and thus were not classified as social behavior in this category.

There were two main concerns in formulating these categories. First it had to be possible to determine an individual's activity state from his ongoing motor patterns alone; the recording of an individual as being in a particular state did not depend on either the preceding or following activities. Secondly, the categories "feeding" and "moving" were chosen so as to differentiate bouts of feeding at any one location from movements between feeding locations. Thus, it is believed that the pattern of feeding and moving by individuals reflected the spatial distribution of food resources. Other activities, which were put into the two general categories of resting and social behavior, are of interest in their own right, but were not particularly pertinent to the activity study (SLATKIN, in prep.).

\section{SAMPLING METHODS}

Two sampling methods were used to measure activity patterns. The first method, 
called day-long or gross samples, was designed to determine the fraction of time spent in each of the four activity states. The second method, called short-term or detailed samples, was designed to characterize changes in behavior that took place over a short time scale. The first technique is called an instantaneous sample and the second, a focal animal sample by J. Altmann (1974).

For the gross samples, the activity state of the focal animal was recorded each minute, on the minute, from 0900 to 1800 hours, except for predetermined breaks for lunch and rest. The proportion of minute-by-minute records for which the focal male was in each of the four activity states is an estimate of the fraction of time spent in each state and is referred to as the time budget of that male. The focal male followed on any day was arbitrarily selected from a subset of four group living males, initially including $B J$. After $B J$ 's departure, he was sampled continuously for seven days; later, samples were taken only on the three males that remained in the group. Gross samples were taken on each of the three males remaining in the group for eight full days. In the gross samples the focal individual was out of sight on average for $31 \%$ of the observation period. This yielded sample sizes of from 268 to 435 minute-byminute records for any one day. The assumption is made that these records collected when the male was visible were representative of that individual's activities throughout the day.

In addition, two or three detailed samples were obtained each day on the focal individual. In the detailed samples, all transitions from one activity state to another were recorded for a period of 30 minutes. Samples were begun each day at around 0900,1200 , and 1600 . No information for the gross samples was lost during detailed samples since the activities on the minute could be obtained directly from the detailed sample data sheets. These detailed samples were designed to measure the average duration of each of the activities and the degree of autocorrelation of activities, as will be explained below. In contrast, the gross sample records do not contain this short-term information. A total of 419,464 , and 481 minutes of detailed samples were obtained on the three group living males; the solitary male was the subject of detailed samples for 375 minutes.

\section{COMPARISON OF TIME BUDGETS}

$B J$ 's time budget was sampled for only two days prior to his departure from the group. Thus, the sample of his activity while group living is insufficient to allow sta-

Table 1. Comparison of time budgets of group living males and solitary male. Table shows the $\%$ of time in each activity state and standard deviation of the $\%$ 's.

\begin{tabular}{lllll}
\hline & Feeding & Moving & Resting & Social behavior \\
\cline { 2 - 5 } Group living males & & & \\
I & $55.9 \pm 10.6$ & $23.8 \pm 5.2$ & $15.9 \pm 8.7$ & $4.4 \pm 3.0$ \\
II & $52.6 \pm 10.3$ & $25.9 \pm 6.9$ & $17.1 \pm 7.4$ & $4.4 \pm 2.9$ \\
III & $54.6 \pm 5.9$ & $27.9 \pm 4.1$ & $14.1 \pm 5.6$ & $3.4 \pm 2.3$ \\
$\quad$ Average & $54.4 \pm 8.9$ & $25.9 \pm 5.4$ & $15.7 \pm 7.2$ & $4.7 \pm 2.7$ \\
Group living & & & & \\
Male $B J$ & & & & \\
(2 days only) & $47.1 \pm 1.7$ & $26.9 \pm 4.9$ & $18.7 \pm 4.0$ & $7.3 \pm 0.7$ \\
Solitary & $46.8 \pm 8.4$ & $21.9 \pm 3.1$ & $29.2 \pm 7.7$ & $2.1 \pm 5.9$ \\
\hline
\end{tabular}


tistical comparison with his activity while solitary. Table 1 presents the available data on his activity as a group living and as a solitary male as well as information on the time budgets of the three group living males. It will be seen that there was very little variability in the time budgets of the group living males and thus we assume that comparison of $B J$ 's time budget as a solitary male to that of the three group living males will yield the same results as a direct comparison between $B J$ 's time budgets as a group living and as a solitary male. Briefly, during the week that $B J$ was sampled as a solitary male, he spent on average $7 \%$ less time feeding than did group living males. By the end of the seven days of observation, both observers independently noted that $B J$ had apparently lost weight, but it is unlikely that a $7 \%$ reduction in food intake would be sufficient to produce noticeable weight changes in so short a period of time. Dehydration and reduced piloerection are alternative explanations of the apparent weight loss. During this period, $B J$ spent less time moving and in social behavior and considerably more time resting than did group living males.

Table 2. Average duration (in minutes) of activities of group living and solitary males, from detailed time samples. (The solitary male did not engage in social behavior during detailed samples and thus no data on this behavior are included. Also, the number of detailed samples on $B J$ while group living is insufficient to estimate activity bout durations.)

\begin{tabular}{llll}
\hline & Feeding & Moving & Resting \\
\hline Group living males & & & \\
I & .749 & .261 & .451 \\
II & .551 & .321 & .282 \\
III & .759 & .304 & .546 \\
$\quad$ Average & .656 & .295 & .459 \\
Solitary Male & & & \\
$\quad \begin{array}{l}\text { Male } B J \text { (solitary } \\
\text { only) }\end{array}$ & 1.143 & .300 & .556 \\
\hline
\end{tabular}

From the detailed samples, the average duration of activity bouts was determined and these results are summarized in Table 2 . Although the average duration of moving and resting was approximately the same for the solitary male as for the three group living males, there was a substantial difference between the average feeding bout length of the solitary male and the group living males. Specifically, the average duration of a feeding bout by $B J$ as a solitary male was about $67 \%$ longer than the average duration of feeding bouts of group living males. This effect is probably due to the fact that $B J$ 's feeding bouts were not interrupted by conspecifics.

\section{Autocorrelation of Activities}

Also from the detailed samples, the degree of autocorrelation of each activity was measured. The autocorrelation of an activity is defined as the conditional probability, $p_{i j}(t)$, that an individual would be in the $i$ th activity state at time $T+t$ given that it was in the $i$ th activity state at time $T$ regardless of any other states it may be in between these times (SLATKIN, in prep.). The autocorrelation function $P_{F F}(t)$ for feeding and $P_{M M I}(t)$ for moving are shown for the solitary male in Figure 1 and for group living males in Figure 2. These curves are approximately exponential in shape, beginning, of necessity, at 1 and approaching an asymptote equal to the probability of the individual 

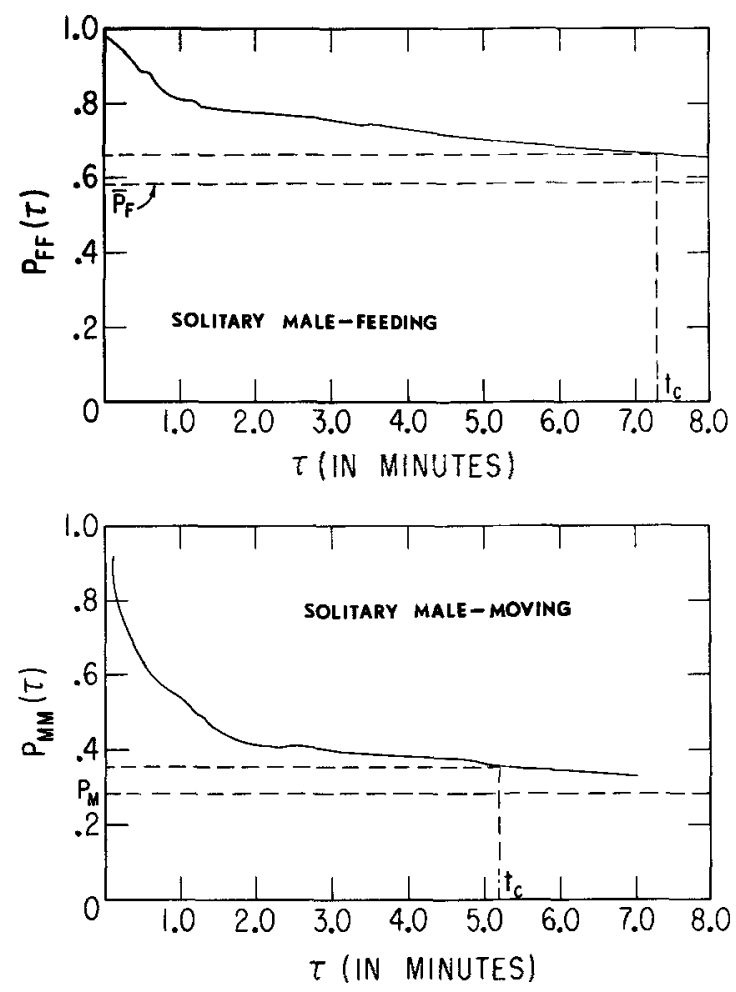

Fig. 1. Autocorrelation function of activities for adult male $B J$ while solitary. $P_{F F}(t)$ and $P_{M M}(t)$ are the fractions of time $B J$ was observed to be feeding and moving respectively given that he was feeding and moving at time $T$ in the past. $\bar{P}_{F}$ and $\bar{P}_{M}$ are the average fraction of time spent feeding and moving. $t_{c}$ marked on each graph is approximately the time for $\boldsymbol{P}$ to reduce the initial distance to the asymptote by $90 \%$.

being in the ending state independently of the beginning state, or, in other words, the proportion of time spent in each activity.

Of particular interest is the rate at which the autocorrelation function approaches the asymptote. For example if the autocorrelation curves shown were exponential, then the formula for the curves would be

$$
P_{i i}(t)=1-\left(1-\bar{P}_{i}\right) e^{-t / t_{c}}
$$

and $t_{c}$ would be the time it takes for the function to go from the initial distance from the asymptote, $1-\bar{P}_{i}$, to a distance $1 / e$ or $37 \%$ of the initial distance. If $t_{\mathrm{c}}$ is small then the activity shows a low degree of autocorrelation, or the individual has little "memory" (in a statistical sense) of previous activity. If $t_{c}$ is larger then the activity is highly autocorrelated and the individual retains some "memory" or effect of previous activity. The autocorrelation functions shown in Figures 1 and 2 are not quite exponential, but they are sufficiently close that we can employ a similar measure of correlation time. Thus, $t_{c}$ for these figures is defined as the time it takes for the function to reduce the initial distance to the asymptote by $90 \%$. The values of $t_{\mathrm{c}}$ for all autocorrelation functions are shown in Figures 1 and 2, and while it is possible to have a different value of $t_{c}$ for each function, for these data one value of $t_{c}$ is sufficient to describe both 

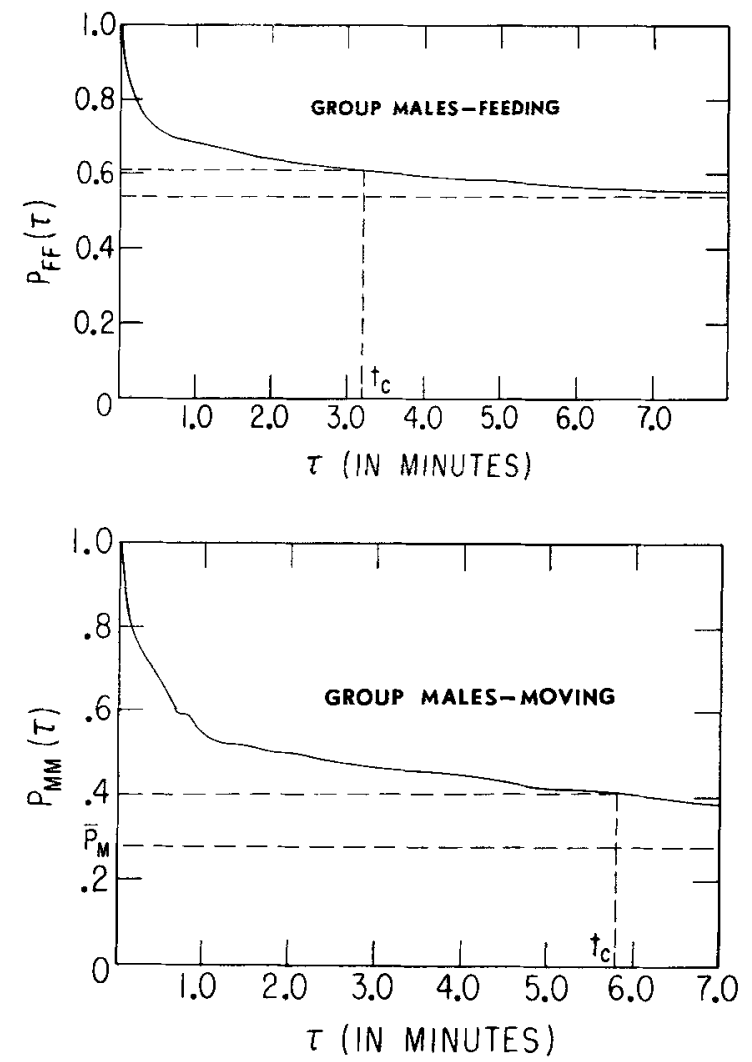

Fig. 2. Autocorrelation functions for feeding and moving of the three group living males. Notation is the same as Fig. 1.

functions shown in Figure 1 for the solitary male and another value of $t_{c}$ describes both functions shown in Figure 2 for the group males. These figures show that the autocorrelation time for the solitary male was approximately $50 \%$ greater than that of the group living males. In sum, then, the solitary male spent less time feeding, had longer feeding bouts, and had a higher degree of autocorrelation of activity than did group living males.

\section{Discussion of Activity Patterns}

Quite possibly some of the differences seen in the time-budget of the solitary male when compared to that of the group living males could have resulted from physical or psychological trauma following his wounding and emigration from the group. However, the average duration of feeding bouts for an individual is probably most strongly influenced by the amount of food that individual can gather without moving from a single location, i.e., changing from the feeding activity state to the moving activity state. In this regard, a "food patch" has been defined as any collection of food items (e.g., a bush with edible berries) on which an individual can feed continuously without having to change position through gross locomotory movements (SLATKIN, in prep.). Thus, the average duration of feeding bout length for a solitary 
male is presumably a measure of the average size of food patches in the Amboseli study area. On the other hand, the average duration of feeding bouts for group living males is probably affected both by ecological constraints (e.g., food patch distribution) and by social interactions with other group members. Group living males are influenced by their conspecifics either directly in interactions such as supplantation of one individual from a food patch by another individual, or indirectly through the tendency of the activity of neighboring individuals to be correlated. Additionally, insofar as two or more individuals share the same food patch, the patch is effectively made smaller for both individuals and the duration of feeding bouts on that patch is probably reduced.

The above analysis of average duration of feeding bouts for group living males and the solitary male in the Amboseli study area indicates that one consequence of life in a social group is a substantial shortening of feeding bout duration or, in other words, food patch size is effectively reduced, probably due to the social factors discussed above. The fact that the average duration of moving bouts for the solitary male and the group living male were approximately equal is an indication that the distance between food patches was the same for both group and nongroup living males.

Autocorrelation times are effected by two factors: the average duration of the activity and the tendency to return to the same activity. Animals return to feeding more frequently than expected at random if food resources are clustered together or clumped in their spatial distribution. In the present study, however, both solitary and group males were living in the same habitat with the same resource distribution. Thus, on the assumption that there was no difference in clump size selection, any differences in the degree of autocorrelation of activities should be the same as the differences in activity bout duration. In fact, the autocorrelation time of the solitary male increased by roughly the same proportion as the duration of his feeding bouts. Thus, the degree of autocorrelation apparently was affected by social interactions only through the effects of social interactions on feeding bout durations.

\section{SUBSEQUENT HISTORY OF MALE BJ}

From 11 August through late October, 1971, $B J$ was observed only intermittently. On 14 August 1971, $B J$ was seen near his former group, Alto's group; several individuals in the group stood bipedally and grunted toward $B J$, but no direct physical contact took place. On 26 August $1971, B J$ was seen traveling with another group in the Amboseli population, BTF group (HAUSFATER, 1975), and was in fact in consort with a pre-ovulatory female. His leg wound was closed and a compact scab was visible. $B T F$ group was chased by $A l t o$ 's group and $B J$ ran away with $B T F$ group. On 27 August 1971, $B T F$ group, including $B J$, again was chased by Alto's group. No direct physical contact between $B J$ and any member of Alto's group was observed on either occasion. By 29 September 1971, however, $B J$ was no longer with $B T F$ group and shortly thereafter was again observed leading a solitary existence.

On 26-27 October, 1971, BJ returned to Alto's group. On the 26th, male $B J$ was seen near the group just after their descent from the sleeping trees. He was chased by adult 
male Stubby, then first ranking in Alto's group, for about one hour in an agonistic sequence similar to those described above for 8 and 11 August 1971. On 27 August $1971, B J$ casually walked into the group just before their evening ascent into the sleeping grove and though he was displaced several times by the first and second ranking males in the group, no overt aggression was directed toward him. Subsequently, $B J$ was third ranking male in the group, the same rank he had occupied prior to his departure in August, 1971. Further details of BJ's return to Alto's group are given by HaUsFater (1975).

On or about 15 November $1971, B J$ defeated the first and second ranking males in Alto's group in several agonistic bouts and from mid-November, 1971, until the end of HAUSFATER's study in September, 1972, $B J$ was first ranking adult male in the study group. In June, 1973, $B J$ was still with Alto's group, but limped badly from a broken leg or dislocated knee; he was seventh ranking among eight adult males. In May-August, 1974, $B J$ was sixth ranking out of twelve adult males in the group; his locomotion had returned to normal. $B J$ remained middle-to-low ranking in Alto's group until his disappearance and presumed death in March, 1976 (D. PosT \& J. Altmann, pers. comm.).

\section{CONCLUSIONS}

Traditionally, the existence of a solitary male has been viewed as something of a curiosity or an aberrant occurrence in an otherwise group living species. However, the phenomenon of a male leaving a social group, spending part of his life as a solitary individual, and then rejoining the same or another group may be an important feature of the life-history and development of male yellow baboons (HAUSFATER, 1975). At the very least, the information presented above indicates that a solitary male, even when injured, is not necessarily destined to die or to have a low reproductive potential. Certainly, there is no evidence to suggest that solitary males are at a disadvantage compared to group living male, at least not with respect to food intake. Nevertheless, it should be clear that the study of solitary individuals, in baboons and in other social species, has great potential both for our understanding of the basic ecological constraints on behavior and activity patterns and for our understanding of the life cycle of maturing individuals.

Acknowledgments. We wish to thank Stuart and Jeanne Altmann for their encouragement and support of this project. This research was supported by grants from the National Institute of Mental Health and the National Science Foundation.

\section{REFERENCES}

AltmanN, J., 1974.Observational study of behavior: sampling methods. Behaviour, 49 : 227267.

Altmann, S. A. \& J. Altmann, 1970. Baboon Ecology. University of Chicago Press, Chicago.

BuRTon, F. D., 1972. The integration of biology and behavior in the socialization of Macaca sylvana of Gibraltar. In: Primate Socialization, F, E. PoIR IER (ed.), Random House, New York, pp. 29-62. 
CoHEN, J. E., 1969. Natural primate troops and a stochastic population model. Amer. Nat., 103: 455-577.

Hausfater, G., 1975. Dominance and Reproduction in Baboons. Contributions to Primatology, Vol. 7. Karger, Basel.

KaufmanN, J. H., 1965. A three-year study of mating behavior in a free-ranging band of rhesus monkey. Ecology, 46: 500-512.

Kawai, K., K. Yoshiba, S. Ando, \& S. Azuma, 1968. Observations on the solitary male among Japanese monkeys: A pilot report for a socio-telemetrical study. Primates, 9: $1-12$.

Koford, C. B., 1966. Population changes in rhesus monkeys: Cayo Santiago, 1960-1964. Tulane Stud. Zool., 13:1-7.

LINDBuRG, D. G., 1969. Rhesus monkeys: mating season mobility of adult males. Science, 166: 1176-1178.

NishidA, T., 1966. A sociological study of solitary male monkeys. Primates, 7: 141-204.

Nozawa, K., 1972. Population genetics of Japanese monkeys: I. Estimation of the effective troop size. Primates, 13: 381-393.

SADE, D. S., 1968. Inhibition of son-mother mating among free-ranging rhesus monkeys. Sci. Psychoanal., 12: 18-38.

SimONDS, P. E., 1973. Outcast males and social structure among bonnet macaques (Macaca radiata). Amer. J. Phys. Anthropol., 38: 599-604.

- Received March 1, 1975; Accepted May 24, 1975

Authors' Addresses: Montgomery Slatkin, Department of Biophysics and Theoretical Biology, University of Chicago, Chicago, Illinois 60637, U.S.A.; GLENN HAUSFATER, Departments of Psychology and Biology, University of Virginia, Charlottesville, Virginia 22903, U.S.A. 